\title{
RICHARDS, KEITH. (2003). QUALITATIVE INQUIRY IN TESOL. HAMPSHIRE: PALGRAVE MACMILLAN.
}

Qualitative Inquiry in TESOL by Keith Richards is a book that is described by many as far from weaknesses of having "narratives that are too frequently disrupted by heavily-jargoned lists and descriptions" (Tafaghodtari 2009: 272). Qualitative Inquiry in TESOL is a thoughtful insight into qualitative inquiry (QI). It offers definitions of QI and differentiates it from other types of research. It also offers detailed descriptions of the interview and observation process, as well as the analysis of spoken interaction.

Qualitative Inquiry in TESOL by Keith Richards highlights the fact that research is a process. This book is a necessity for anyone who needs to do a qualitative research, conduct a good interview, observe with attention and collect and analyse spoken interaction successfully. Qualitative Inquiry in TESOL is, thus, an excellent source of information for fresh, as well as experienced researchers in the teaching of English as a second/foreign language. Qualitative Inquiry in TESOL highlights a valuable link between research and teaching English.

Qualitative Inquiry in TESOL was published by PALGRAVE MACMILLAN in 2003 (number of pages: 322). The book contains six chapters and an epilogue:

1. The Nature of Qualitative Inquiry

2. Interviewing

3. Observation

4. Collecting and Analysing Spoken Interaction

5. Planning a Project

6. Analysis and Representation

Epilogue: Qualitative Inquiry and Teaching.

After each chapter, there is also a Reading Guide offering an insight into further reading and research. What is interesting about Qualitative Inquiry in TESOL is that each chapter is divided into a three-level exploration of QI. The author of this book explains the purpose of dividing the content of chapters into levels in detail. Thus, Level 1 is an introductory level to QI. It is dedicated to introductory teacher preparation programme at the diploma level. Level 2 is Intermediate to Advanced level (Masters and 
Doctoral). Level 3 serves as a source of information at more advanced levels - Doctoral and Post-Doctoral. Nevertheless, the author perceives combination of these levels as the best possible solution for a successful QI researcher. In accordance with the three levels, the book is also divided into three parts, three interrelated wholes: I Orientation, II Investigation and III Application.

We perceive the first chapter entitled "The Nature of Qualitative Inquiry" as an encyclopaedia of QI, since it describes the nature of QI. It explains the characteristics of QI and differentiates it from other types of research. The chapter contains Level 1: the Inquiring Mind which provides us with a definition of research and leads through purpose, design, procedure, analysis. Level 2: Working within a Tradition presents seven core traditions in qualitative research. These are, as follows: ethnography, grounded theory, phenomenology, case study, life history, action research, conversation analysis. Level 3: Paradigmatic Choices emphasizes the existence of paradigms and their representation in terms of ontology (our beliefs about reality) and epistemology (our beliefs about knowledge).

From an interesting comparison by Oakley (1981: 41) in which interviewing is compared to marriage, to the essence of qualitative interviews, the second chapter "Interviewing" introduces us to interview types and techniques, as well as interview structure. In our opinion, this chapter highlights an important fact that before we conduct an interview, we need to learn how to listen or even, behave during an interview. This is a leitmotiv in Level 1: learning how to listen. Level 2: issues of structure, deals with structure of an interview, focusing on opening and closing an interview as the two important phases. Level 3: aspects of analysis, deals with the analysis in talk and analysis of talk. It offers a four-level model which includes questions, distortions, relationships and interviewees, and which helps us cope with the technique analysis of talk. Analysis in talk deals with transcription features: pauses, overlap, emphasis, fillers, intonation, unclear words, non-verbal features. Qualitative Inquiry in TESOL makes a strong connection between interviewing and observation, which is best seen in the transition from Chapter 2, "Interviewing" to Chapter 3, "Observation". Namely, the purposefulness is found as an important characteristic of both interviewing and observation.

The third chapter "Observation" examines the role of the purposefulness of observation. Level 1: learning to see, leads us through the observational skills, open setting for observation, the observer's paradox, the ethics, note taking. Level 2: participant observation deals, among other things, with four key features for observation and these are: setting, 
people, behavior, systems. Level 2: participant observation highlights the author's tendency to praise a research diary in a research process. Level 3: structured observation makes a distinction between open and closed observation. A distinction between open and closed observation may help us to navigate our research and organize the data by coding, first general sense of setting and activities related to it and later, behaviour.

The fourth chapter, "Collecting and Analysing Spoken Interaction" offers an insight into transcription. At the very beginning, it also presents useful transcription conventions. Level 1: getting started, acts as a guide for novice teachers on how to make successful recordings. In order to start recording, we need to have the equipment. Level 2: developing an analysis, focuses on analysing the transcription and three criteria in relation to transcription decisions (fitness for purpose, adequacy and accuracy). Fitness for purpose, as its name says, is concerned with our decisions about what to transcribe and how to transcribe. Adequacy is about finding a balance between simplified and detailed transcription. Finally, accuracy in transcribing is shifting, since there is no a single, correct transcription - it all depends on the ones who listen and transcribe. Level 3: different approaches to analysis deals with the three different approaches to analysis, that is, conversation analysis, interactional sociolinguistics and critical discourse analysis.

The fifth chapter of Qualitative Inquiry in TESOL, "Planning a project" deals with the procedures for a research project. After useful guidelines for conducting a qualitative research, this chapter offers an insight into planning a research project. The chapter presents three phases in conducting a project: thinking, reading and, finally, writing (realization). Level 1: the personal project is, as any Level 1 in this book, an introductory remark on planning a project - what do we need for a successful project planning, Level 2: resources for project planning, gives us the ideas on how to go about planning a project and presents some data collection methods. Level 3: wider engagement is concerned with the participatory action research, a specific form of leadership in this research, and a considerable part of this level is dedicated to a link between research and theory.

There is a specific opinion on integrating theory in our research. It should not be introduced too early, because the theory has a tendency to dominate our mind. Also, it should not be introduced too late because the theory needs to energize our mind and inspire us to do research. Thus, it should be introduced naturally. After this, we perceive theory as a pillar present throughout our research. What we, as novice teachers, like among other pieces of advice in the fifth chapter is the author's opinion on 
keeping a small notebook full of everything that we find interesting about our own teaching, that is, self-reflection and reflecting on practice by focusing on what we would like to know more about in our work.

The last chapter "Analysis and Representation" is divided into three levels, as follows. Level 1: discovery highlights the important characteristics of qualitative research (openness, inquisitiveness, honesty, authenticity, legitimacy, transparency). In addition, this level presents six qualities of QI. Level 2: analysis, as its name says, describes qualitative analysis and the complex connection between data and analysis. This level is particularly interesting because it is an insight into characteristics of qualitative analysis. Level 3: interpretation deals with what is reliable and what is valid in our readings (i.e. reliability and validity).

"Epilogue: Qualitative Inquiry and Teaching" comes as an inspiring conclusion to qualitative inquiry and its relationship with teaching. There are two aspects that connect teaching with research: recognition of complexity and respect for difference. Teaching and research are complex, because they are both science and an art. One sentence, like an echo, needs to reappear in our attempts to teach and do research: both teaching and research are a combination of ratio and sēnsus.

In conclusion, we must add that Qualitative Inquiry in TESOL has shown us that research is not a bogey. It certainly IS time-consuming, it requires a lot of preparation, planning and setting the scene before it even starts not to mention the interpretation and analysis of research results. However, research is an insightful process, which includes everything from perception, understanding to intuition.

\section{REFERENCES}

Tafaghodtari, M. (2009): "Qualitative inquiry: New alternatives for the applied linguist”. Language Teaching 42, 277-282.

Oakley, A. (1981): "Interviewing women: a Contradiction in Terms," In: H. Roberts (ed.), Doing Feminist Research (pp. 31-61). London: Routledge $\&$ Kegan Paul. 